\title{
Parabolic dish collector for domestic purposes with novel receiver design
}

\author{
M. Chahoud
}

\begin{abstract}
Two parabolic dish collectors with different properties referring to the reflective material, the receiver design and the tracking mechanism are tested in this work in order to examine their thermal performance as part of a residential solar water heater. In both cases, a parabolic dish manufactured originally for satellite television receiving has been used as a carrier for the reflective material which consists of aluminum strips in the first collector and glass mirrors in the second one. Novel receiver construction has been tested for each collector. Using the new construction it is possible to renounce the automatically tracking mechanism in the north -south direction in order to minimize the installation costs. Efficiency measurements of the collector with aluminum strips yielded 0.59 for the intercept efficiency and $2.9 \mathrm{~W} / \mathrm{m}^{2} \mathrm{~K}$ for the first order coefficient; whereas the values for the collector with glass mirrors are 0.71 and $2.1 \mathrm{~W} / \mathrm{m}^{2} \mathrm{~K}$ respectively.

Published test reports of flat-plate and evacuated tube collectors are studied in order to assess the thermal performance of the designed collectors in this work. The efficiency curve of the collector with the glass mirrors lies higher than the average efficiency curve of flat-plate collectors and evacuated tube collectors.
\end{abstract}

Keywords-- Solar energy, Solar water heating, Parabolic collector.

\section{INTRODUCTION}

Hot water is an essential requirement for industry as well as for the domestic sector. In Syria fossil fuel is generally used for water heating with the well known consequences of environmental impacts. Besides, the dramatically growing prices of fossil fuel have in the last ten years encouraged its substitution by renewable energy sources. Thus, it is important to exploit the huge solar energy potential existing in Syria, which can be expressed through the average global horizontal solar radiant flux of $5.2 \mathrm{kWh} / \mathrm{m}^{2} /$ day or $1.9 \mathrm{MWh} / \mathrm{m}^{2} /$ Year [1].

Solar water heaters in Syria are not widely used in comparison with other Mediterranean countries like Cyprus, Turkey or Greece due to low prices of conventional energy resources and the high costs of solar water heater systems existing in the Syrian market.

Flat plate and evacuated tube collectors are worldwide the most used collectors for domestic solar water heaters. Both types are investigated in details by many research groups [2-11].

M. Chahoud is a member of the Atomic Energy Commission of Syria (AECS), P. O. Box 6091, Damascus, Syria,

Tel.: +963 11 6111927; fax: +963 116112289 E-mail: pscientific@aec.org.sy (M. Chahoud).
TABLE I

NOMENCLATURES

\begin{tabular}{cl}
\hline \hline Symbol & Quantity \\
\hline $\mathrm{A}_{\mathrm{c}}$ & Collector aperture $\left(\mathrm{m}^{2}\right)$ \\
$\mathrm{c}_{\mathrm{w}}$ & Water heat capacity $\left(\mathrm{J} / \mathrm{kg} .{ }^{\circ} \mathrm{C}\right)$ \\
$\mathrm{G}_{\mathrm{b}}$ & Direct solar radiation $\left(\mathrm{W} / \mathrm{m}^{2}\right)$ \\
$\mathrm{k}_{\mathrm{c} 0}$ & Collector intercept efficiency \\
$\mathrm{k}_{\mathrm{c} 1}$ & First order coefficient of the \\
& collector efficiency $\left(\mathrm{W} / \mathrm{m}^{2} \mathrm{~K}\right)$ \\
$\mathrm{k}_{\mathrm{c} 2}$ & second order coefficient of the \\
& collector efficiency $\left(\mathrm{W} / \mathrm{m}^{2} \mathrm{~K}^{2}\right)$ \\
$\dot{m}$ & Water mass flow rate $(\mathrm{kg} / \mathrm{sec})$ \\
$\mathrm{n}_{\mathrm{c}}$ & Collector efficiency \\
$\dot{Q}$ & Gained energy rate or power $(\mathrm{W})$ \\
$\mathrm{T}_{\mathrm{a}}$ & Ambient air temperature $\left({ }^{\circ} \mathrm{C}\right)$ \\
$\mathrm{T}_{\mathrm{in}}$ & Collector inlet water temperature \\
& $\left({ }^{\circ} \mathrm{C}\right)$ \\
$\mathrm{T}_{\text {out }}$ & Collector outlet water temperature \\
& $\left({ }^{\circ} \mathrm{C}\right)$ \\
$\mathrm{y}_{\mathrm{c}}$ & Collector heat loss parameter \\
\hline \hline
\end{tabular}

Parabolic solar dish collectors are mainly investigated in compound with stirling engines in order to produce electricity [12-17]. The thermal exploitation of solar dish collectors is investigated in several fields such as direct steam generation [18-19]. On the other hand parabolic dish collectors for solar water heating have still not yet obtained enough attention. Therefore no such collectors are available commercially for residential solar water heating systems.

The use of solar dish collectors for water heating doesn't require high conditions regarding water pressure and temperature. This point will be exploited in the receiver design in the present work.

Test reports published by the Solar Rating and Certification Corporation (SRCC) of 21 unglazed, 206 glazed flat-plate and 46 evacuated tube collectors are studied, in order to compare the thermal performance of the designed collector in this work with the most available collector types.

\section{DESCRIPTION OF THE DESIGNED SYSTEM}

The used parabolic dish has a diameter of $170 \mathrm{~cm}$ and a focal length of $86 \mathrm{~cm}$. This dish was originally manufactured in order to receive satellite television signal. In the first collector the surface of the dish was covered with high reflective aluminum strips of $10 \mathrm{~cm}$ width and $0.4 \mathrm{~mm}$ thickness.

The strips take almost the same parabolic shape of the dish because of their relatively small width in comparison to the focal length. The increasing of the strip width would lead to an increase in mismatching between the dish surface and the strips. The diameter of the focal spot 
of the dish was experimentally determined; it was approximately $10 \mathrm{~cm}$. This value is very important for the designing of the receiver, whose width must be at least equal to the focal spot diameter. Fig. 1a shows schematically the designed receiver. It consists of a copper tube grid with $30 \mathrm{~cm}$ length and $15 \mathrm{~cm}$ width. The inner diameter of the tubes is $8 \mathrm{~mm}$, whereas their outer diameter is $10 \mathrm{~mm}$. The grid was covered with a copper sheet of $0.5 \mathrm{~mm}$ thickness. This cover acts as an absorbent surface for the solar radiation in the spaces between the copper tubes. The sheet was welded to the tubes, in order to achieve good thermal conductivity. The tubes and the cover plate were thermally black painted. An insulating layer of $2 \mathrm{~cm}$ thickness, made of glass wool is placed above the copper sheet, whereas the outside cover is made of $0.4 \mathrm{~mm}$ thick aluminum plate. The lower part of fig. 1a shows a cross section of the receiver belonging to the dashed line of the upper part.
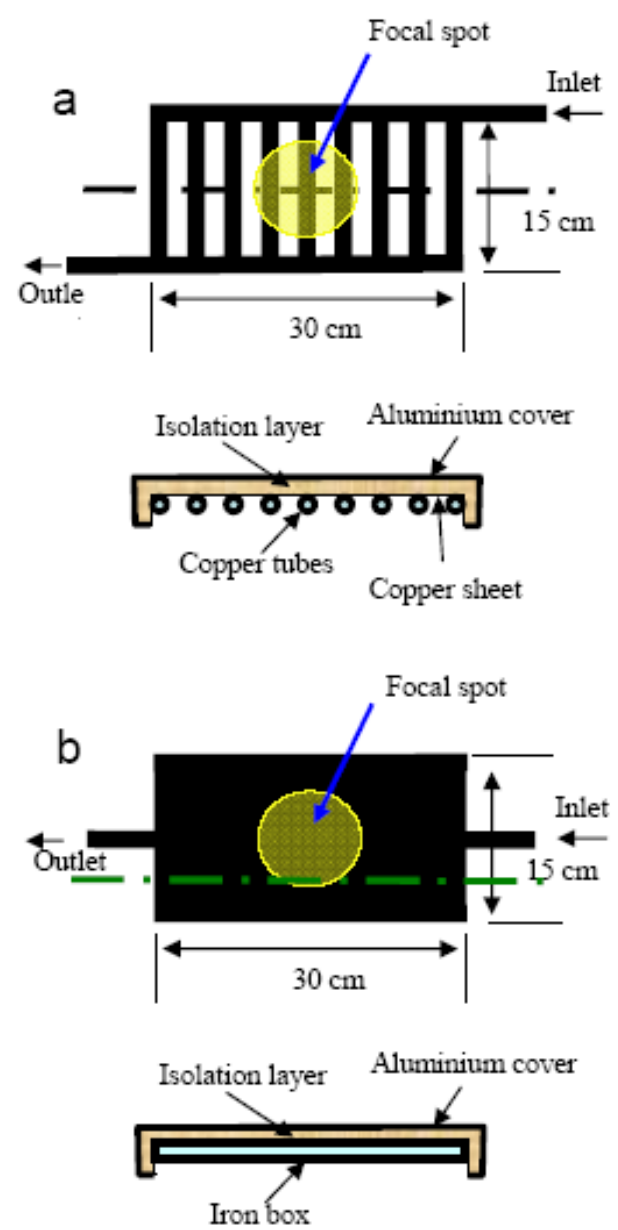

Fig. 1. Schematic illustration of the designed receiver for the dish with the alu-strips (a) and for the dish with glass mirrors (b).

This design differs significantly from the well known cavity (or semi-cavity) receiver [20-21], where the heat transfer fluid (HTF) flows along a spiral tube covering the inside surface of a sphere. The cavity receiver ensures minimal heat loses due to air convection. This aspect is important if the temperature difference between the HTF and the air is high. This difference is in the solar water heating systems much lower than in electricity generation applications such as solar dishes with stirling engines. Therefore the convection heat loses are small and the use of the above described receiver is justified.

The elongated shape of the receiver allows the replacing of the automatically tracking of the sun in the north-south direction by manually adjustment of the collector angle one time every two weeks. When the sun moves in the north - south direction, the focal spot moves also but in opposite way. However it remains on the bottom surface of the receiver for about two weeks, because of the elongated shape. The automatically tracking in the eastwest direction is absolutely needed and remains uninfluenced by the manually adjustment in the other direction.

The use of the designed receiver and the manually adjustment of the collector every two weeks save the costs which would be needed for a tracking device in the north - south direction. In this manner the installation cost of the heating system is clearly reduced.

The volume of the used water tank is 100 liter. This tank is thermally isolated with a $2.5 \mathrm{~cm}$ thick glass wool layer. It is connected to the inlet and outlet of the receiver with thermally isolated flexible plastic tubes. A water pump with a nominally mass flow rate of $2 \mathrm{~kg} / \mathrm{min}$ is used to circulate the water between the tank and the receiver.

The second dish has $10 \mathrm{~cm} * 10 \mathrm{~cm} * 2 \mathrm{~mm}$ glass mirrors acting as the reflective material instead of the aluminum strips. The mirrors have been stuck to the parabolic dish using silicon paste. The receiver of this dish consists of a water conducting box made of $1 \mathrm{~mm}$ thick iron sheets. The dimensions of this box as well as the thermal isolation are chosen identical to those of the first dish for comparison purposes (Fig. 1b). The sun is tracked automatically in the east-west and north-south directions. The receiver material choosing was made with respect to the costs and the thermal conduction properties. In the first collector high thermal conductivity is required because the heat has to be transferred laterally for relatively long distances $(\sim 1.5 \mathrm{~cm})$ to the copper tubes which conduct the heat medium (water). Therefore copper is preferred more than iron despite the higher costs.

In the second collector the heat has to be transferred perpendicular to the surface of the receiver for a short distance of $1 \mathrm{~mm}$ (thickness of the receiver material). Hence moderate heat conductivity is sufficient and iron is chosen as material for this receiver.

The use of a water conducting box is very advantageous regarding the heat transfer from the receiver surface to the HTF. However this design is not suitable for applications with high pressure requirement, because the box geometry cannot stand high pressure values such as the conducting tube geometry.

The heat losses of the receiver are very marginal because of its small surface relative to the total collector surface. Therefore no cover transparent glass for the receiver is needed. The use of such cover will lead to decrease of the thermal efficiency due to the losses according to the reflections at the glass surface.

The material costs of the first collector are approximately 200 USD whereas these costs increase for the second collector to approximately 300 USD due to the tracking mechanism in the north-south direction. The costs can be 
clearly reduced if the production is carried out industrially for large amount of collectors.

\section{RESULTS AND DISCUSSION}

The dependence of the thermal efficiency of a solar concentrating collector on the design and operational factors is given by the following equation [2]:

$n_{c}=k_{c 0}-k_{c 1} \cdot y_{c}-k_{c 2} \cdot G_{b} \cdot y_{c}^{2}$

Where $\mathrm{y}_{\mathrm{c}}$ is defined as the difference between the water inlet temperature and ambient temperature divided by the direct solar radiation intensity.

Usually the second order term is neglected $\left(\mathrm{k}_{\mathrm{c} 2}=0\right)$, so that (1) becomes of first order:

$n_{c}=k_{c 0}-k_{c 1} \cdot y_{c}$

In order to determine the collector intercept efficiency $\mathrm{k}_{\mathrm{c} 0}$ and the first order coefficient $\mathrm{k}_{\mathrm{cl}}$, the following measurements were carried out on 16 August 2006 for the first collector and on 20 October 2008 for the second collector: The ambient air temperature $\left(\mathrm{T}_{\mathrm{a}}\right)$, the direct solar radiation $\left(G_{b}\right)$, the inlet water temperature $\left(T_{i n}\right)$, the outlet water temperature $\left(\mathrm{T}_{\text {out }}\right)$, the water flow rate $(\dot{m})$. The measurements were performed between 10 and 16 o'clock in Damascus. The climate was suitable for carrying out the measurements. The sky was cloudless, whereas the wind speed was about $10 \mathrm{~km} / \mathrm{h}$.

The tracking device and the circulation pump were started to operate at 9 o'clock am in order to guarantee steady state operating conditions of the solar heater at 10 .

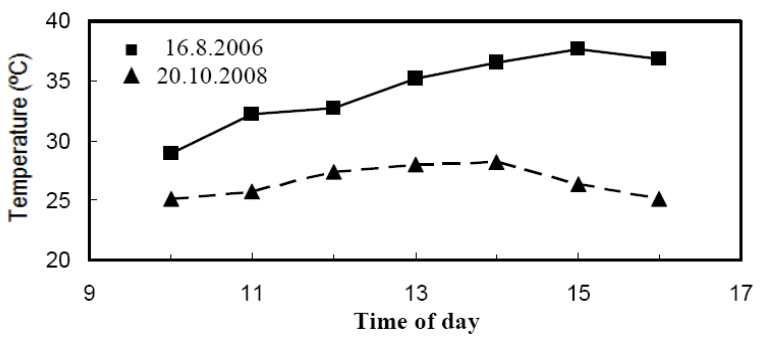

Fig. 2. Measured ambient temperature $\left(\mathrm{T}_{\mathrm{a}}\right)$.

Fig. 2 shows the ambient air temperature during the two measuring days. The temperature rises continuously on 16 august 2006 from $28.9^{\circ} \mathrm{C}$ at 10 o'clock until it reaches its maximum of $37.6{ }^{\circ} \mathrm{C}$ at 15 o'clock. The difference between the highest and lowest temperature on 20. 10 . 2008 was much smaller. The highest temperature was $28.2^{\circ} \mathrm{C}$, whereas the lowest temperature was $25.1^{\circ} \mathrm{C}$.

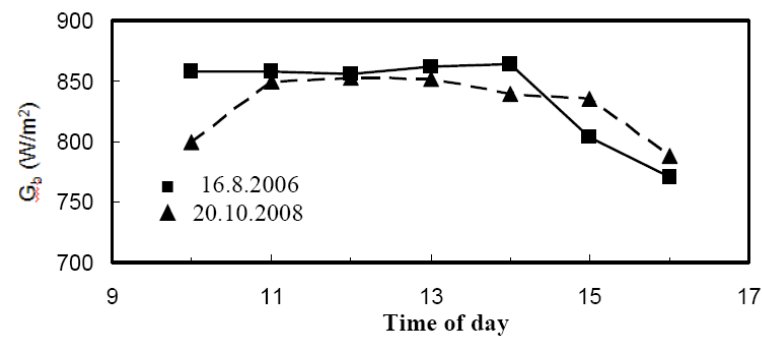

Fig. 3 Measured direct solar radiation $\left(G_{b}\right)$.
The intensity of the direct solar radiation is depicted in figure 3. The two measured curves show similar dependence on time if we take into account the shift of one hour in the official local time between summer and winter. The average direct solar radiation on 16. 8. 2006 was $839 \mathrm{~W} / \mathrm{m}^{2}$, whereas it was $831 \mathrm{~W} / \mathrm{m}^{2}$ on 20.10 . 2008.

The direct solar irradiance power varies between $83 \%$ and $86 \%$ of the total solar power in both days. The tested solar collectors can only utilize the direct solar radiation because of their parabolic shape. Therefore only the direct solar power will be taken into account for the determination of the thermal performance of the designed collectors. This disadvantage of the parabolic collectors in contrast to the flat-plate collectors, which utilize direct and indirect solar radiation, is compensated through the continuous tracking of the sun.

The gained energy rate can be calculated using the following well known formula:

$\dot{Q}=\dot{m} \cdot c_{w} \cdot\left(T_{\text {out }}-T_{\text {in }}\right)$

Consequently, the efficiency can be written as follows:

$n_{c}=\frac{\dot{Q}}{A_{c} \cdot G_{b}}=k_{c 0}-k_{c 1} \cdot y_{c}$

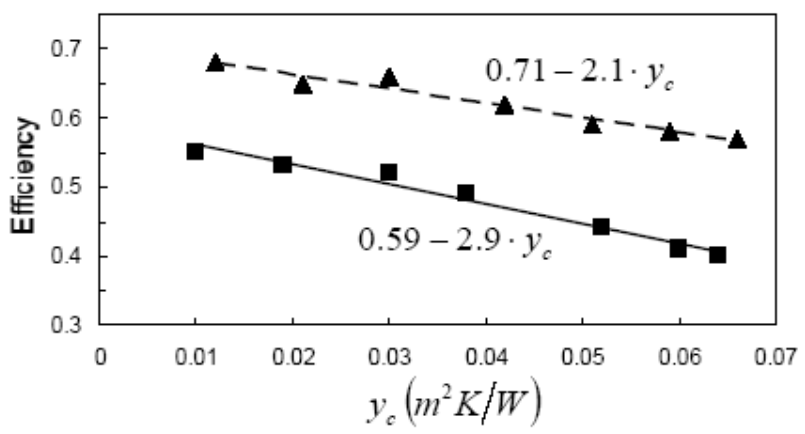

Fig. 4. Measured efficiency of the collector with the Alustrips ( $\square)$ and the collector with the glass mirrors ( $\boldsymbol{A})$.

Figure 4 shows the measured efficiency curves of the two designed parabolic collectors as a function of the heat loss parameter $y_{c}$. The intercept efficiency of the first collector is 0.59 , whereas it increases to 0.71 for the second collector. This indicates that the reflectivity of the glass mirrors and the absorbency of the iron box receiver are better than those of the aluminum strips and the copper grid receiver, respectively.

The first order coefficient $\mathrm{k}_{\mathrm{c} 1}$ decreases from $2.9 \mathrm{~W} / \mathrm{m}^{2} \mathrm{~K}$ for the first collector to $2.1 \mathrm{~W} / \mathrm{m}^{2} \mathrm{~K}$ for the second collector. This improvement may result from the decreasing of the receiver surface which is effectively exposed to the ambient air. This surface is in the first collector the sum of the tubes surface and the copper plate surface (fig. 1), whereas it consists only of the iron box bottom surface in the second collector.

In order to compare the thermal performance of the designed parabolic dish collector with that of the flatplate collectors and evacuated tubes, test reports published by the SRCC of 21 unglazed and 206 glazed flat-plate collectors as well as 46 evacuated tube 
collectors are analyzed and evaluated regarding the intercept efficiency $\mathrm{k}_{\mathrm{c} 0}$ and the first order coefficient $\mathrm{k}_{\mathrm{c} 1}$. The average values of $\mathrm{k}_{\mathrm{c} 0}$ and $\mathrm{k}_{\mathrm{c} 1}$ for each type of collectors are depicted in table II. For comparison the measured values of the second designed collector in this work are also given in this table.

TABLE II

COMPARISON OF TESTED COLLECTORS BY THE SRCC AND THE SECOND COLLECTOR OF THIS WORK.

\begin{tabular}{lccc}
\hline \hline & $\begin{array}{c}\text { NUMBER OF } \\
\text { TESTED } \\
\text { COLlectors } \\
\text { (SRCC) }\end{array}$ & $\begin{array}{c}\text { Average } \mathrm{k}_{\mathrm{c1}} \\
\left(\mathrm{W} / \mathrm{m}^{2} \mathrm{~K}\right)\end{array}$ & $\begin{array}{c}\text { Average } \mathrm{k}_{\mathrm{c0}} \\
(\%)\end{array}$ \\
\hline Unglazed flat-plate (a) & 17.3 & 81.8 & 21 \\
glazed flat-plate (b) & 5.1 & 69.5 & 206 \\
Evacuated tubes (c) & 1.59 & 44.5 & 46 \\
This work (d) & 2.1 & 71 & - \\
\hline \hline
\end{tabular}

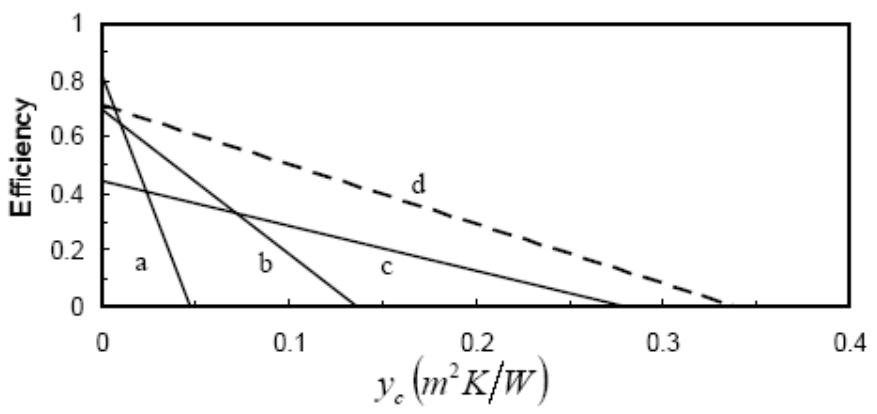

Fig. 5. Efficiency curves of an average unglazed (a), glazed (b) and evacuated tube collector (c) and the designed collector in this work $(\mathrm{d})$.

Fig. 5 shows the efficiency curves corresponding to the average values of $\mathrm{k}_{\mathrm{c} 0}$ and $\mathrm{k}_{\mathrm{c} 1}$ given in table II. Additionally, the efficiency curve of the second designed collector in this work is also depicted for comparison. From fig. 5 it is clear that the efficiency of the parabolic dish collector (d) is superior to the glazed flat-plate (b) and evacuated tube collectors (c) in the whole range of $y_{c}$. Whereas the efficiency of the unglazed flat-plate collector (a) is higher For $\mathrm{y}_{\mathrm{c}}<0.01 \mathrm{~m}^{2} \mathrm{~K} / \mathrm{W}$ corresponding to small temperature increasing.

Taking into account the moderate material costs and the superior thermal performance of the second designed parabolic dish collector, it can be concluded in a first evaluation that this type of collectors is competitive to the widely used flat-plate and evacuated tube collectors in the domestic solar water heating sector.

\section{CONCLUSION}

In this work two parabolic dish collectors with novel receiver design has been tested as part of a solar water heating system.

Measurements have been carried out in order to compare the thermal performance of the two collectors.

The intercept efficiency $\mathrm{k}_{\mathrm{c} 0}$ for the first collector equals 0.59 whereas it amounts to 0.71 for the second collector. This indicates that the conversion from radiation energy to heat energy of the second collector is better than of the first one.
The first order efficiency $\mathrm{k}_{\mathrm{c} 1}$ decreases from $2.9 \mathrm{~W} / \mathrm{m}^{2} \mathrm{k}$ for the first collector to $2.1 \mathrm{~W} / \mathrm{m}^{2} \mathrm{k}$ for the second collector, which means that the heat losses of the receiver of the second collector are $27 \%$ smaller than of the first collector.

Comparisons between the second designed collector and tested collectors by the SRCC of the types flat-plate and evacuated tubes results in better values of $\mathrm{k}_{\mathrm{c} 0}$ and $\mathrm{k}_{\mathrm{c} 1}$ for the designed collector in this work.

Considering the moderate material costs and the high thermal efficiency it can be concluded that the parabolic dish collector is competitive to the commonly used flatplate and evacuated tube collectors for solar water heating.

\section{ACKNOWLEDGMENT}

The author wishes to thank Prof. I. Othman, the general director of the Atomic Energy Commission of Syria, for his continuous support, guidance and encouragement for researches.

\section{REFERENCES}

[1] A. Al-Mohamad, Renewable energy resources in Syria, renewable energy 24 (2001) 365-371.

[2] S. A. Kalogirou, Solar thermal collectors and applications, Progress in energy and combustion science 30 (2004) 231-295.

[3] N. M. Villar et. al., Numerical 3-D heat flux simulations on flat plate solar collectors, Solar Energy 83 (2009) 1086-1092.

[4] W. Eisenmann et. al., On the correlations between collector efficiency factor and material content of parallel flow flat-plate solar collectors, Solar Energy 76 (2004) 381-387.

[5] T. Matuska et. al., Façade solar collectors, Solar Energy 80 (2006) 1443-1452.

[6] M. Khoukhi et. al., Theoretical approach of a flat-plate solar collector taking into account the absorption and emission within glass cover layer, Solar Energy 80 (2006) 787-794.

[7] V. Badescu et. al., Optimum fin geometry in flat plate solar collector systems, Energy Conversion and Management 47 (2006) 2397-2413.

[8] I. Budihardjo et. al., Performance of water-in-glass evacuated tube solar water heaters, Solar Energy 83 (2009) 49-56.

[9] Y. Kim et. al., Thermal performances comparisons of the glass evacuated tube solar collectors with shapes of absorber tube, Renewable Energy 32 (2007) 772-795.

[10] G. L. Morrison et. al., Water-in-glass evacuated tube solar water heaters, Solar Energy 32 (2004) 135-140.

[11] I. Budihardjo et. al., Natural circulation flow through water-inglass evacuated tube solar collectors, Solar Energy 81 (2007) 1460-1472.

[12] R. Pitz-Paal, Concentrating solar technologies - The key to renewable electricity and process heat for a wide range of applications, World renewable energy congress VII (WREC 2002), Cologne, Germany.

[13] L. D. Jaffe, Test results on parabolic dish concentrators for solar thermal power systems, Solar Energy 42 (1989) 173-187.

[14] F. Nepveu, Thermal model of a dish/Stirling systems, Solar Energy 83 (2009) 81-89.

[15] I. Tlili et. al., Analysis and design consideration of mean temperature differential Stirling engine for solar application, Renewable Energy 33 (2008) 1911-1921.

[16] S. A. Kalogirou, Solar Thermal Power Systems, Solar Energy Engineering (2009) 521-552.

[17] B. Kongtragool et. al., A review of solar-powered Stirling engines and low temperature differential Stirling engines, Renewable and Sustainable Energy Reviews 7 (2003) 131-154.

[18] N. D. Kaushika et. al., Performance of a low cost solar paraboloidal dish steam generating system, Energy Conversion and Management 41 (2000) 713-726.

[19] N. S. Kumar et. al., Numerical investigation of natural convection heat loss in modified cavity receiver for fuzzy focal solar dish concentrator, Solar Energy 81 (2007) 846-855. 
[20] N. S. Kumar et. al., Comparison of receivers for solar dish collector system, Energy Conversion and Management 49 (2008) 812-819.

[21] W.T. Xie et. al., Numerical and experimental analysis of a point focus solar collector using high concentration imaging PMMA Fresnel lens, Energy Conversion and Management 52 (2011) 2417-2426.

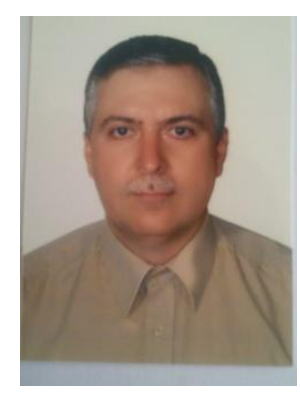

Mohsen Chahoud was born in Homs, Syria, in 1966. He received the Dipl-Ing. Degree in electrical engineering from the Technical University of Braunschweig in Germany in 1994. In 1995 he joined the Institut für Halbleitertechnik of the technical university of Braunschweig. In 1998 he received there the $\mathrm{PhD}$ degree. Since 1999, he has been at the atomic Energy Commission of Syria (AECS), where his main interest lies in the solar energy applications. 